\title{
HABITAÇÃO EM MUNICÍPIOS
}

PAULISTAS:

\author{
CONSTRUIR POLÍTICAS OU “RODAR” PROGRAMAS?
}

\author{
RaQuel Rolnik \\ Rodrigo Faria Gonçalves IACOVINI \\ DANIELle KLINTOWITZ
}

\begin{abstract}
R E S U M O : O artigo analisa os atores, arenas e processos efetivamente envolvidos em investimentos habitacionais nos municípios do estado de São Paulo, buscando compreender se esses investimentos convergiam ou não com os processos participativos instaurados na última década. Embora a hipótese inicial de que não haveria tal convergência tenha sido confirmada, constatou-se que isso não se devia à disponibilidade reduzida de recursos próprios municipais ou à sua baixa capacidade institucional como se imaginava até então. A falta de iniciativa em se estabelecer açôes autônomas, aderentes às necessidades locais e pactuadas nos âmbitos de participação instituídos, e a plena adesão municipal ao modelo do Programa Minha Casa, Minha Vida resultam, na realidade, de uma postura pragmática dos governos municipais que, com um minimo de esforço institucional, asseguram ganhos importantes aos principais players da política.
\end{abstract}

P A L A V R A S - C H A V E : politica habitacional; autonomia municipal; processos decisórios; arenas participativas; Programa Minha Casa, Minha Vida.

\section{INTRODUÇÃo}

Os anos 1990 representaram avanços no campo institucional do Direito à Cidade no Brasil, a partir da incorporação à Constituição dos princípios da função social da cidade e da propriedade, do reconhecimento dos direitos de posse em assentamentos informais e da participação direta dos cidadãos nos processos decisórios sobre a política urbana, pilares centrais da chamada "agenda de reforma urbana" (ROLNIK; KLINTOWITZ; IACOVINI, 2011; SANTOS JR., 2007). Foi também no mesmo período que os processos de descentralização federativa e de fortalecimento e autonomia dos poderes locais foram sendo progressivamente implantados, limitados tanto pelos constrangimentos do ajuste macroeconômico vivido nos anos 1990 como pela alta dose de continuidade do sistema político e da forma de financiamento do desenvolvimento urbano prevalente no país (ARRETCHE, 2000). Tendo como foco municípios paulistas, este artigo apresenta os principais resultados de pesquisa ${ }^{1}$ cujo objetivo principal foi desvendar as fontes de recursos assim como as arenas, atores e processos através dos quais têm sido definidos os investimentos em habitação, estabelecendo as convergências (ou não) desses percursos com os processos de planejamento participativo experimentados pelas cidades.

A hipótese inicial era de que, apesar dos esforços institucionais e de instauração de processos de planejamento territorial participativos na década de 2000,

1 Trata-se da pesquisa "Planejamento territorial e financiamento do desenvolvimento urbano em municípios do estado de São Paulo: marchas e contramarchas", realizada entre 2011 e 2013 pela equipe do Laboratório Espaço Público e Direito à Cidade da Faculdade de Arquitetura e Urbanismo da Universidade de São Paulo (LabCidade - FAUUSP), com apoio da Fundação de Amparo à Pesquisa do Estado de São Paulo (FAPESP). Além dos autores, participaram da pesquisa Joyce Reis Ferreira da Silva, Vitor Coelho Nisida, Julio Sarti Caldeira, Ana Paula de Oliveira Lopes e o Professor Renato Cymbalista. 
2 Compôs a análise: receita tributária, despesas, receitas de transferências estaduais e de transferências federais. Fontes: Fundação Sistema Estadual de Análise de Dados (SEA$D E)$ e Finanças do Brasil (FINBRA). (Disponível em: <http://www.seade.gov.br/ banco-de-dados/>; <http:// www.tesouro.fazenda.gov. br/contas-anuais>. Acesso em: fev. 2014).

3 Analisados os dados de produção fornecidos pela Companhia de Desenvolvimento Habitacional e Urbano do Estado de São Paulo (CDHU) sobre a produção estadual e pelo governo federal sobre a produção através do Programa Minha Casa, Minha Vida (PMCMV)

4 Foram avaliados: 1) capacidade institucional para implementação de políticas habitacionais (abrangendo presença de órgão, fundo de habitação, Plano Local de Habitação de Interesse Social, cadastro); e 2) capacidade institucional para regulação do solo (possuir Plano Diretor, Zoneamento, Le de Parcelamento do Solo, Zonas Especiais de Interesse Social e Legislação Específica de Regularização Fundiária). Fonte: Pesquisa sobre o Perfil dos Municípios Brasileiros (MUNIC) 2012 - Instituto Brasileiro de Geografia e Estatística (IBGE). (Disponível em: <http://www.ibge.gov.br/ home/estatistica/pesquisas/pesquisa_resultados. php?indicador=1\&id pesquisa $=89>$. Acesso em: 10 fev. 2014).

50 indicador - que vem sendo desenvolvido e utilizado há anos pela equipe de pesquisa - serve como uma ponderação em relação à situação habitacional e urbana dos municípios, uma proxy das condições urbanísticas do município. As variáveis que compõem o indicador são: abastecimento de água, presença de saneamento básico, coleta de lixo, fornecimento de energia elétrica e características do- estes não teriam definido as açóes municipais posteriores em funçáo: 1) da disponibilidade reduzida de recursos próprios municipais, o que levaria a uma dependência das transferências do governo federal e estadual e, portanto, das condiçôes políticas e técnicas definidas por estes; e 2) do limitado poder decisório das arenas participativas constituídas.

Um estudo de natureza quantitativa foi realizado abrangendo o conjunto de municípios do estado com indicadores sobre autonomia financeira ${ }^{2}$, produção habitacional ${ }^{3}$, capacidade institucional ${ }^{4}$ e evoluçâo das condiçôes de adequação domiciliar ${ }^{5}$ na última década. Em seguida foram realizados estudos de caso (pesquisa documental e entrevistas ${ }^{6}$ ) em seis municípios ${ }^{7}$ - Hortolândia, Jacareí, Registro, Osasco, Ferraz de Vasconcelos e Praia Grande ${ }^{8}$ - onde foram avaliados os atores, as arenas e os processos concretos que orientaram os investimentos habitacionais, possibilitando testar as hipóteses e responder às questóes que nortearam a pesquisa.

\section{PRODUÇÃO HABITACIONAL, AUTONOMIA FINANCEIRA E CAPACIDADE INSTITUCIONAL}

A produção habitacional brasileira é marcada por decisôes e investimentos historicamente concentrados na União. Desde os anos 1930, os municípios tiveram um maior protagonismo apenas em um breve momento, com a crise do Sistema Financeiro Habitacional (SFH) e do Banco Nacional da Habitação (BNH), extinto em 1986 (BONDUKI, 1998; AZEVEDO, 2007; MELO; JUCÁ FILHO, 1990).

Aliadas à promulgação da Constituição de 1988, a extinção do banco e as pressóes concretas a nível local por ações de melhoria nas condições habitacionais induziram um certo processo de descentralização das políticas habitacionais. Nesse momento, todos os estados brasileiros eram ainda dotados de companhias estaduais de habitação, que haviam sido constituídas para participar da política implantada pelo $\mathrm{BNH}$ (ARRETCHE, 2000). Segundo Melo e Jucá Filho (1990), observou-se entáo uma "estadualização da política habitacional" com a proliferação de açóes estaduais e municipais, que passaram a estabelecer prioridades e a delinear novos modelos de políticas sociais de acordo com suas capacidades administrativas e recursos fiscais disponíveis.

A partir de meados da década de 1990, a produçáo habitacional do estado de São Paulo teve um extraordinário desempenho quantitativo, fato que se deve à reabilitação da companhia estadual de habitação - Companhia de Desenvolvimento Habitacional e Urbano do Estado de São Paulo (CDHU) - e, sobretudo, à destinação anual de $1 \%$ do Imposto sobre Circulação de Mercadorias e Prestação de Serviços (ICMS) para a área, o que possibilitou a construção de unidades habitacionais em massa (ROYER, 2002). Essa produção passou a ser gerida pelo governo estadual, com pouca participação direta das prefeituras, ainda que estas devessem, muitas vezes, comprometer-se com a contrapartida do terreno e da infraestrutura. Essa contrapartida, entretanto, não garantia a participação da prefeitura na contratação das construtoras nem na definição dos potenciais beneficiários das unidades residenciais, ficando assim os "ativos" políticos do programa no âmbito da companhia estadual (ARRETCHE, 2000).

Segundo a CDHU 9 , até o ano de 1986 foram atendidos 19 municípios (3\% de um total de 572), já em 1999 - intervalo de pouco mais de uma década - esse total 
chegou a 250.000 unidades em 515 municípios (80\% de um total de 645 municípios), incluindo todos os municípios estudados pela pesquisa.

No mesmo período, na esfera municipal, começaram a ser realizadas, sobretudo, ações no campo da urbanização e regularização de assentamentos precários. Poucos municípios, contudo, tiveram capacidade institucional e financeira para implementar uma política habitacional de fato em seus territórios. No caso de Osasco, desde o final dos anos 1980 se investe em urbanização através de um processo de "conta-gotas" (CALDEIRA, 2014), não constituindo, entretanto, uma política planejada e estruturada.

Apenas nos anos 2000 o governo federal retoma os investimentos em habitação. Em 2003, com o Governo Lula, instituiu-se o Ministério das Cidades, conquista da coalizão pela Reforma Urbana. Com poucos recursos, sua primeira equipe apostou na institucionalização de sua pauta, a exemplo da aprovação do Sistema Nacional de Habitação de Interesse Social (SNHIS) e do Fundo Nacional de Habitação de Interesse Social (FNHIS) em 2005. No modelo proposto, a adesão ao SNHIS por parte dos entes federativos é voluntária e se dá a partir do compromisso em elaborar um plano local (estadual, distrital ou municipal) de habitação e de constituir um fundo específico para habitação de interesse social (HIS), com um conselho gestor com representação dos segmentos da sociedade ligados à área e eleitos democraticamente. Os recursos seriam destinados às transferências fundo a fundo, condicionadas ao oferecimento de contrapartida do ente federativo. Até o momento, esse modelo não foi implantado, apesar da adesão dos municípios e constituição de conselhos e fundos.

Entre 2007 e 2009, dois novos programas federais - Programa de Aceleração do Crescimento (PAC) e Programa Minha Casa, Minha Vida (PMCMV) - modificaram o cenário da produçáo habitacional, desmontando o modelo do SNHIS ${ }^{10}$ (CARDOSO; ARAGÃO; ARAUJO, 2011; IPEA, 2011). Em 2008, a crise internacional foi o pretexto para ampliação definitiva do volume de recursos destinados ao setor, recolocando a habitação como uma questão central da agenda nacional através do lançamento do PMCMV. Concebida desde o início como política de grande escala, tinha como meta inicial a construção de 1 milhão de moradias, posteriormente ampliada para 3,4 milhôes na sua segunda fase, em 2011. Seu objetivo é criar condiçóes de ampliação do mercado habitacional para atendimento das famílias com renda correspondente a, no máximo, 10 salários mínimos. No programa, o governo federal disponibiliza os recursos para subsídio e para financiamento, solicitando a apresentação de projetos para as empresas. Estas, por sua vez, apresentam propostas de empreendimentos com o número de unidades e nas localidades que desejam, as quais passam por uma avaliação da Caixa ${ }^{11}$, que contrata a operação, acompanha a execução da obra e libera recursos alocados pela União.

Com uma meta ambiciosa e um grande volume de recursos (quase 3\% do Produto Interno Bruto (PIB) nacional em 2012), o PMCMV já se tornou o grande protagonista da produção habitacional. Em São Paulo, por exemplo, onde a CDHU (até então principal agente na provisão pública de habitação) produziu aproximadamente 140.000 unidades no período de 10 anos (2000 a 2010), o PMCMV produziu o mesmo número em apenas 2 anos (2009 a 2011). Em entrevistas com técnicos da Secretaria de Habitaçãoo ${ }^{12}$, constatou-se, inclusive, que os municípios teriam deixado de buscar parcerias com a CDHU para produção habitacional e miciliares. Fonte: Censo 2010 - IBGE. (Disponível em: <http://www.ibge.gov br/home/estatistica/populacao/censo2010/default. shtm>. Acesso em: $10 \mathrm{fev}$. 2014).

6 Foram realizadas, no total, 47 entrevistas distribuídas nos seis municípios estudados, sendo 17 entrevistas com gestores públicos, $10 \mathrm{com}$ membros do legislativo municipal, 03 com agentes da Caixa Econômica Federa (CEF), 07 com empresários e 10 com membros da sociedade civil organizada. Como forma de preservar a identidade do entrevistado, será identificado o autor das citações utilizadas apenas como Gestor $X$, Vereador $\mathrm{Y}$, etc.

7 Foram selecionados municípios com mais de 20 mil habitantes; que apresentaram o índice de adequação domiciliar (2000 a 2010) superior à média estadual (de 12\%). que tiveram produção habitacional através do PMCMV e CDHU; e que receberam transferências federais voluntárias. Dos 19 municípios encontrados, foram escolhidos municípios que estivessem nas faixas alta (Osasco, Praia Grande, Jacareí e Hortolândia) e baixas (Registro e Ferraz de Vasconcelos) de autonomia financeira.

80 critério de escolha incluiu, ainda, a localização desses municípios, abrangendo municípios metropolitanos e não metropolitanos e inseridos em diferentes regiões do estado.

9 Fonte: Dados de atendimento da CDHU. (Disponível em: <http://www.cdhu. sp.gov.br/producao-new/ producao-habitacional. asp>; <http://www.cdhu.sp. gov.br/programas_habitacionais/apresentacao.asp>. Acesso em: 15 jun. 2012).

10 Inicialmente, para o período de 2007 a 2010, o PAC previa aporte de R\$ 55,9 bilhões para a área habitacional, incluindo as contrapartidas de $\mathrm{R} \$$ 9,3 
bilhões de estados e municípios (BRASIL, 2010). $\mathrm{Na}$ sua primeira fase, $\mathrm{O}$ PMCMV teve orçamento inicial de $\mathrm{R} \$ 34$ bilhões.

11 Caixa Econômica Federal (CEF), banco público ligado ao governo federal. 12 Entrevistas com Gestores Municipais 1 e 2, realizadas em 2012.

13 Entrevista com Gestor Municipal 3, realizada em 2012.

14 Entrevista com Gestor Municipal 4, realizada em 2013.

15 Sequer essa estratégia foi bem sucedida, tendo sido a gestão municipal obrigada a, até mesmo, devolver recursos por não ter sido capaz de utilizá-los adequadamente, tanto pela sua estrutura institucional muito precária quanto por desvio de verbas, de acordo com denúncias.

16 Entrevistas com Gestores Municipais 1, 2, 3, 4, $5,6,7,8,9,10$ e 11 , realizadas entre 2012 e 2013.

17 Fonte: Elaboração própria a partir de dados da Fundação SEADE sobre a situação dos municípios paulistas. (Disponível em: <http://www.seade.gov.br/ banco-de-dados/>. Acesso em: 10 fev. 2014). passaram a focar no PMCMV, uma vez que este contaria com procedimentos bem mais simples de operacionalização. À exceção de Osasco, em todos os demais municípios estudados houve redução do número de unidades produzidas pelo $\mathrm{CDHU}$.

Paralelamente à retomada dos investimentos federais na década de 2000, constatamos praticamente a ausência de ações implementadas exclusivamente com recursos municipais nos casos estudados. Se antes alguns deles usavam recursos próprios (mesmo que fossem reduzidos) para realização de ações aderentes à realidade municipal, hoje, nesse novo contexto de larga oferta de recursos federais (amarrados com normativas e procedimentos pré-definidos), os municípios deliberadamente abrem mão dessa possibilidade de autonomia na definição da política habitacional e redirecionam suas açóes no sentido de apenas potencializar sua capacidade de captaçáo de verbas federais. Muitos deles têm, no máximo, centrado seus esforços em usar seu capital político em articulaçóes para fazer "rodar" tais programas e políticas em seus territórios. Apenas em Hortolândia foi detectado um programa de fornecimento de materiais de construçáo para melhoria habitacional que era de iniciativa exclusiva municipal.

No caso específico de Osasco ${ }^{13}$, que contava com ações de regularização e urbanização pontuais desenvolvidas com recursos próprios, esse redirecionamento foi deliberado. Em Ferraz de Vasconcelos, a gestão municipal também direcionou suas ações nesse sentido. A própria criação de uma Secretaria de Habitação objetivava criar uma instância que fosse capaz de gerar projetos para captar recursos federais ${ }^{14}$. Não se tratava da criação de uma secretaria para formular e implementar uma política habitacional municipal, mas para aproveitar o momento de grande liberaçáo de recursos ${ }^{15}$.

Em Hortolândia, esse redirecionamento fez com que os programas que vinham sendo desenvolvidos pelo município - notadamente de regularização fundiária de assentamentos informais - fossem transformados, majoritariamente, em açôes de remoçáo e reassentamento de ocupaçóes através de empreendimentos produzidos pelo PMCMV.

Quando se questiona o porquê desse redirecionamento, a primeira resposta dos gestores $^{16}$ é a falta de recursos municipais para investimentos na área. Os entrevistados foram unânimes em afirmar a existência de poucos recursos próprios e que dependeriam fortemente das transferências, sendo sua arrecadaçáo pequena.

Assim como os gestores, nossa hipótese inicial era de que a falta de iniciativas próprias de produção habitacional nos municípios se deveria a sua baixa autonomia financeira e institucional. Arretche (2005) alerta que governos desprovidos de autonomia para obter - por meio de taxação - recursos para atender às demandas da sociedade local tendem a incorporar à sua agenda as orientaçôes e decisões políticas de outros níveis de governo que, de fato, têm o poder sobre os recursos financeiros. Como dependeriam majoritariamente de transferências intergovernamentais para os investimentos em habitação e desenvolvimento urbano, os municípios estariam reféns, portanto, das políticas e decisôes federais, que, além de altamente mediadas pelo sistema político-partidário, não seriam necessariamente convergentes com as demandas e necessidades locais.

A análise dos dados sobre finanças municipais demonstra, realmente, que ainda há uma grande dependência municipal em relação às transferências realizadas pelos outros entes federados. Apenas 21\% dos municípios de São Paulo têm mais de 50\% de seus recursos oriundos de receita própria; enquanto $17 \%$ dependem de transferências para compor mais de $70 \%$ de seu orçamento ${ }^{17}$.

Contudo, se esses dados são analisados de forma mais detalhada, verifica-se 
que não se pode, necessariamente, afirmar que os municípios estejam impossibilitados de realizar açóes autônomas ${ }^{18}$, pois possuem, em alguma medida, capacidade de realizar investimentos. Constatamos também que o serviço da dívida (Juros mais Amortização de Empréstimos) não ultrapassa 4\% da composiçâo de despesas dos municípios estudados, evidenciando o baixo endividamento dos municípios, que praticamente não contrataram Operaçôes de Crédito. O recurso ao endividamento, se bem utilizado, poderia ser extremamente útil no caso de investimentos em habitação e infraestrutura urbana, que requerem grandes volumes iniciais, mas não implicam, posteriormente, num grande aumento de despesas de custeio - com pagamento de pessoal, material, etc.

Apesar de ser, junto com o Imposto sobre Serviços de Qualquer Natureza (ISS), a principal fonte de receita tributária dos municípios brasileiros, estes não parecem ter qualquer disposição em majorar o Imposto Predial e Territorial Urbano (IPTU), seja através da aplicação de alíquotas maiores em casos de imóveis vazios ou subutilizados, seja na atualização da planta genérica de valores, a qual na maioria dos casos encontra-se muito defasada. Em municípios estudados ${ }^{19}$, existiria, inclusive, uma diretriz clara do prefeito de que em nenhuma hipótese se mexeria em tributos como forma de aumentar arrecadação, tendo em vista que se trataria de uma medida politicamente impopular.

Diante desse panorama das finanças dos municípios e comparando com a média estabelecida pelos municípios paulistas e brasileiros, conclui-se que, apesar de serem ainda majoritariamente dependentes, os municípios estudados têm margem de endividamento e possuem mecanismos para obtenção de mais recursos para realizar suas políticas e investimentos urbanos e habitacionais. Entretanto, os municípios optam por não fazer.

Retoma-se entáo a questáo: por que os municípios parecem estar abrindo mão de sua possibilidade de conduzir, de forma própria e autônoma, as decisóes sobre suas políticas e projetos da área habitacional e, paulatinamente, redirecionam suas açóes no sentido da adesão completa às políticas e programas federais? Frente ao panorama exposto, não se sustenta a hipótese de que se deveria, exclusivamente, à sua baixa autonomia financeira.

Outra hipótese estaria vinculada à sua fragilidade institucional, tanto no plano geral da administração municipal quanto especificamente na área habitacional. Segundo um gestor municipal entrevistado:

Atualmente existe um volume de recursos muito alto que tem sido repassado pelo governo federal para projetos, e isso gera primeiramente um encantamento nos municípios, que acabam buscando obter o máximo possível de projetos, já que isso dá visibilidade à gestão e gera dividendos políticos. Depois desse encantamento, o problema começa já com as contrapartidas. Entretanto, os municípios não estavam acostumados a essa forma de captar recursos, em que você tem que engessar uma parte do seu orçamento em contrapartidas. O que acontece, entâo, em alguns casos, é que cada área ia apresentando projetos e comprometendo contrapartidas, quando a gestáo se dava conta, já havia perdido completamente o controle do orçamento em função das contrapartidas prometidas pelas diferentes secretarias. $\mathrm{E}$ isso nâo é nada organizado ou centralizado, quando se está montando o planejamento orçamentário futuro, a cada dia se descobre uma nova contrapartida de 2 milhóes, 1 milháo prometida por alguma secretaria. ${ }^{20}$
18 Identificamos as principais receitas e despesas, por natureza e por função de Habitação e de Urbanismo nominais (históricos), disponíveis nos últimos quatro anos (2008/2011) em cada um dos municípios estudados. Agrupadas as receitas (em Próprias Transferências e Operações de Crédito) e as despesas (em Correntes, Investimentos, Amortização de Empréstimos e Outras Despesas de Capital), verificou-se o equilíbrio orçamentário (receita total menos despesa total) de cada um deles para o período. Por fim, ao ser calculada a Receita Disponível (formada por Recursos Próprios, Transferências Correntes menos Despesas Correntes e Amortização de Empréstimos), esta foi comparada com o montante global de investimentos declarados pelos municípios. Quando os valores da Receita Disponível encontrada foram inferiores aos de investimento, tomou-se como um possível indicador de que, para o nível de investimento realizado, teria sido necessário contar com operações de crédito e/ou transferências de capital da União ou do Estado; por outro lado, quando estes valores foram superiores, considerou-se que o município tinha receita suficiente para realizar seus investimentos sem necessidade de recursos externos.

19 Entrevistas com Gestores Municipais 1 e 12, realizadas entre 2012 e 2013.

20 Entrevista com Gestor Municipal 12, realizada em 2013. 
21 Entrevista com Gestor Municipal 12, realizada em 2013.

22 Entrevistas com Gestor Municipal 7 e Vereador 1, realizadas em 2012.
Algumas operaçôes, como é o caso do endividamento, ensejam açóes complexas de planejamento e gestáo orçamentária, as quais, muitas vezes, poderiam estar além das atuais possibilidades de operação dos agentes públicos municipais. Mesmo em municípios econômica e institucionalmente mais desenvolvidos, como Osasco, constatou-se em entrevista ${ }^{21}$ com gestores que os poderes públicos municipais não conseguem sequer ter clareza de qual é a sua efetiva margem de endividamento e como ela poderia ser utilizada sem que fossem violados os dispositivos da Lei de Responsabilidade Fiscal.

Destaca-se também a pouca capacidade institucional especificamente para desenvolvimento da política habitacional (BRASIL, 2010; ARRETCHE, 2012; DENALDI, 2011). Segundo Arretche (2012), a maioria dos municípios náo conta com estruturas para desenvolver essa política, como planos locais de habitação ou mesmo órgáos para gestáo, e, quando existem, têm altas taxas de "morte institucional", sendo frequentemente extintos quando um novo prefeito toma posse. Em 2009, o instrumento mais generalizado no país era o cadastro ou levantamento de famílias interessadas em programas habitacionais, presente em $66 \%$ dos municípios paulistas. Arretche (2012) destaca que esse instrumento tem a maior taxa de sobrevivência ao longo do tempo.

Como era esperado, era frágil a situação institucional encontrada nos órgãos e departamentos destinados à habitação nos municípios estudados. Embora alguns contem com uma estrutura mais robusta e proativa (Osasco e Hortolândia), nos demais verificamos estruturas com poucos técnicos e pouca capacidade de gerenciar os projetos em andamento, sem falar na dificuldade em elaborar novos projetos. Em Jacareí, por exemplo, não há órgão da administração direta dedicado à habitação, havendo somente a Fundação Pró-Lar. Segundo os gestores locais ${ }^{22}$, sua função seria basicamente a manutenção do cadastro de famílias e a gestão dos terrenos doados à prefeitura por novos parcelamentos.

Em Ferraz de Vasconcelos, como já mencionado, a criação de uma Secretaria de Habitação é recente e destinava-se, principalmente, a ampliar a possibilidade de captação de recursos federais existentes na área. Nessa mesma cidade, vale a pena mencionar um fato peculiar. Inquirida uma técnica da Secretaria de Habitação sobre o Plano Municipal de Habitação, que segundo levantamentos havia sido realizado com apoio financeiro do governo federal, esta desconhecia a sua existência. Em outra visita realizada, ela afirmou que havia se lembrado e encontrado o plano, tendo nos entregue a única cópia existente para que levássemos conosco, tendo em vista que "ninguém o usaria por lá mesmo".

Apesar dessa e de outras fragilidades, a baixa capacidade institucional náo apareceu como o fator determinante para a inexistência de políticas próprias na área. Na verdade, ela sequer parece uma real questáo para os municípios, pois o novo modelo institucional desenhado para a política nacional de habitação brasileira - que se concretiza basicamente com o PMCMV - parece prescindir da capacidade institucional e financeira dos municípios, já que concentra totalmente a decisão no âmbito federal e transfere a promoção para o setor privado. Não é à toa que a única exigência para que um município possa receber os empreendimentos do programa é a existência de um cadastro.

Portanto, se, por um lado, é verdadeiro que a baixa capacidade dos municípios dificulta a formulação e a execução da política habitacional; por outro, também é verdadeiro que muitos municípios náo buscam criar condiçôes para a melhoria 
dessa capacidade, pois não veem necessidade em se constituir como agentes ativos nessa formulação. O governo federal, por sua vez, deixa de fomentar a capacidade institucional dos municípios (vide a desconstrução do SNHIS) e institui um modelo que prescinde desta. Segundo o discurso de técnicos do Ministério das Cidades e do Ministério da Fazenda (LOUREIRO; MACÁRIO; GUERRA, 2013), o modelo proposto para o PMCMV teria sido adotado justamente em função da avaliaçáo por parte dos gestores federais de que os municípios não possuem capacidade própria de implementação de uma política habitacional. Não se estranha, assim, que em todos os municípios estudados detectou-se a priorização da estratégia de adesão ao programa federal em detrimento da implementação de açóes autônomas aderentes a processos de planejamento local.

\section{ATORES, ARENAS E PROCESSOS}

Para entender essa estratégia municipal e o sucesso do modelo proposto pelo PMCMV, analisamos os atores, arenas e processos localmente envolvidos na definição dos investimentos em habitação, explorando o papel desempenhado e os ganhos obtidos por cada um deles no cenário atual.

\section{OS MUNICÍPIOS}

No modelo do PMCMV, o papel dos municípios passou a ser basicamente o de organizar a demanda (através de cadastros encaminhados à Caixa para a seleção dos beneficiários) e, de modo facultativo, criar condiçóes para facilitar a produção, através da flexibilização da legislação urbanística e edilícia dos municípios e/ou da doação de terrenos. Em relação à alteração da legislação municipal, os exemplos mais evidentes são de Registro e Hortolândia. No primeiro deles, trata-se da aprovação de uma lei específica exclusivamente voltada a incluir o terreno no qual se construiria um empreendimento do PMCMV (Faixa 1) no perímetro urbano do município ${ }^{23}$, requisito do programa. Não foi redesenhado o perímetro inteiro a partir de uma necessidade de expansão de seu território, apenas se incluiu o terreno em questão como um apêndice do perímetro urbano porque a construtora ${ }^{24}$ afirmava que aquele era o único terreno em que "a conta do empreendimento fecharia". Hortolândia, por sua vez, criou uma legislação específica para regular a HIS, flexibilizando parâmetros para viabilizar a rentabilidade da produção do programa ${ }^{25}$.

Foram citados, também, casos em municípios não estudados pela pesquisa, como Sumaré, Mogi das Cruzes, Guarulhos e Sorocaba ${ }^{26}$. Segundo a Construtora $1^{27}$, ela mesma já levou a um prefeito minuta de projeto de lei, pronta para ser entregue e aprovada pela Câmara, que viabilizaria seu empreendimento ${ }^{28}$.

Os municípios poderiam, ainda, facilitar a viabilização do atendimento à demanda de baixa renda através da cessão de terrenos públicos. No entanto, tanto empresários $^{29}$ quanto gestores municipai ${ }^{30}$ afirmaram que a burocratização dos processos de desapropriação, desafetação e doação têm resultado na preferência das empresas em comprar novos terrenos em vez da doação.

O papel mais claramente assumido por todos os municípios, portanto, é a indicação dos beneficiários a serem atendidos pela Faixa 1 do programa a partir de
23 Entrevista com Gestor Municipal 11, realizada em 2012.

24 Entrevistas com Gestor Municipal 11 e com Construtor 2, realizadas em 2012

25 Entrevista com Gestor Municipal 2, realizada em 2012.

26 Entrevista com Construtores 1 e 3 , realizadas entre 2012 e 2013.

27 Entrevista realizada em 2012.

28 Entrevista com Construtor 1, realizada em 2012.

29 Entrevistas com Construtores 1 e 4, realizadas em 2012.

30 Entrevista com Gestor Municipal 12, realizada em 2013. 
31 Entrevista com Gestor Municipal 12, realizada em 2013.

32 Entrevista com Gestor Municipal 12, Vereadores 1, 2, 3 e 4, Construtores 3 e 4 e Agente da Caixa 1 , todas realizadas entre 2012 e 2013.

33 O governo estadual está, atualmente, tentando também ser incluído nessa contagem, tendo em vista o complemento financeiro aportado pelo programa Casa Paulista para produção nos municípios do estado.

34 Vereadores 1, 3, 4 e 5 e Gestores Municipais 12 e 13, realizadas entre 2012 e 2013. um cadastro habitacional atualizado. Além do fato de ser um item relativamente de fácil criação e manutenção (exigindo pouco em termos de capacidade institucional), também podem ser utilizados como cadastro ou fontes de informaçôes habitacionais outros cadastros direcionados às políticas assistenciais.

Ao relegar ao município essa indicação da demanda, o PMCMV permite que continue no plano local a manutenção das velhas gramáticas políticas (NUNES, 2011) de interação entre poder público e eleitores, em que a distribuição de benefícios constitui importante ativo para angariar capital político. Indicar a demanda significa, por um lado, um baixo investimento do ponto de vista financeiro e institucional e, por outro, um grande recurso no sentido de angariar possíveis votos em pleitos municipais.

Percebeu-se também a importância dos benefícios eleitorais proporcionados pela inauguraçáo de novos empreendimentos habitacionais, produtos cujo significado vai além das consideraçóes sobre o seu impacto econômico e social.

É por isso que se investe tanto em obra, por conta da visibilidade que elas geram, do impacto que causa na população, que responde muito rápido a esses investimentos. [...] Tanto que o orçamento do primeiro ano de Plano Plurianual [elaborado para o município] é o mais pesado em previsóes de obras, pois já se tem que pensar em resultados a serem mostrados na campanha de $2016 .^{31}$

Tais obras são, assim, "fatos políticos" de dimensão local, regional e nacional, conferindo legitimidade ao exercício do poder por sua elevada "visibilidade" no conjunto das realizaçóes dos governos (CAMARGOS, 1993). Mais ainda no caso do PMCMV, já que não se trata de qualquer investimento, mas um investimento em habitação, utilizando assim o apelo que a casa própria goza junto à população (RONALD, 2008).

Nesse sentido, é relevante que a responsabilidade da realização do cadastro e da indicação da demanda tenha sido reservada ao município, pois isso possibilita a manutenção de práticas clientelistas e sugere à população que o PMCMV seria resultado também da açáo e do envolvimento da prefeitura, mesmo que isso náo corresponda fielmente à realidade. Isso ficou evidente nos estudos de caso ${ }^{32}$, sendo constantemente mencionados os números do programa e como isso supostamente demonstraria o compromisso das gestôes (tanto federal como municipais) com o tema da habitação.

As inauguraçôes contam não só com a presença dos chefes do executivo e do legislativo local como também, muitas vezes, com a presença de membros do executivo e do legislativo federal. Cada unidade produzida vale para duas contagens, ou seja, o capital político gerado serve tanto para o município quanto para o governo federal ${ }^{33}$.

Embora esperássemos, quando iniciada a pesquisa, encontrar uma atuação mais ativa do Legislativo municipal nos processos decisórios de investimentos habitacionais, foi constatada uma marginalização dos seus membros. Em todos os municípios, foi encontrado um padrão caracterizado por uma larga base de apoio do Executivo na Câmara, formada através da negociação de postos-chaves nas secretarias municipais. Na maioria das entrevistas ${ }^{34}$ em que o tema foi alvo de questionamento, ficou evidente que não há qualquer discussão substancial sobre a política habitacional no 
âmbito parlamentar, mesmo quando se trata da aprovação de leis que alterem parâmetros urbanísticos, conceda isençóes fiscais, etc., ficando todas as definiçôes a cargo do Executivo.

De acordo com os entrevistados, cabe aos parlamentares apenas a mediação de pequenas e pontuais demandas apresentadas pela população, que váo desde o fornecimento de medidas assistenciais e da provisão de materiais de construção $0^{35}$ até a influência sobre a indicação da demanda a ser atendida pelo PMCMV, como em Ferraz de Vasconcelos ${ }^{36}$, Hortolândia ${ }^{37}$ e Praia Grande ${ }^{38}$. Em Registro, por exemplo, segundo entrevista ${ }^{39}$, a prefeitura havia decidido que, depois de formada a lista dos possíveis beneficiários, estes seriam escolhidos através de sorteio. Os vereadores, por sua vez, teriam questionado essa decisão, claramente com a expectativa de que, se realizada de outra maneira, poderiam influenciar no resultado final. Embora o Executivo tenha resistido às pressōes, procedido ao sorteio e fiscalizado os beneficiários após a sua entrada nas unidades; alguns vereadores teriam conseguido, mesmo assim, colocar famílias de suas bases eleitorais em unidades do conjunto após a troca do prefeito.

Diante desse quadro podemos afirmar que políticos locais (tanto do Executivo quanto do Legislativo) se beneficiam do programa, o que nos ajuda a entender por que os municípios estudados têm concentrado seus esforços unicamente na viabilização de empreendimentos do PMCMV em seu território. Trata-se de uma postura pragmática, que capta o máximo de benefícios políticos com um mínimo de esforço institucional e financeiro.

\section{Governo FEDERAL - A CAIXA}

Como já afirmamos, a centralização dos recursos para financiamento define um controle por parte do governo federal sobre as políticas habitacionais (ARRETCHE, 2012, p. 164), o que resulta no controle de importante capital político eleitoral. Náo é de se estranhar que o PMCMV tenha sido lançado em março de 2009, pouco mais de um ano antes do período de disputa eleitoral para presidente. Além de conter os efeitos políticos nefastos que uma crise econômica poderia gerar sobre a sucessão presidencial, a ministra-chefe da Casa Civil, Dilma Rousseff, também foi lançada como "Mãe do Minha Casa Minha Vida", fortalecendo sua candidatura ao cargo de presidente da república.

Um dos pontos centrais dessa nova forma de centralização é possibilitar a superação de qualquer tipo de resistência ao programa que poderia ser oferecida por partidos de oposiçấo em gestôes locais. As relaçôes entre entes federativos estão sujeitas às coalizóes e aos arranjos partidários em todos os níveis. Nesse sentido, os alinhamentos partidários costumavam ser importantes para que o governo federal conseguisse que seus programas fossem implementados no plano local, gerando capital político para seus promotores. Mais uma inovação trazida pelo PMCMV é que, ao menos aparentemente, ele permite que o governo federal supere o "federalismo partidário". Ao delegar a promoção de empreendimentos habitacionais a empresas, o PMCMV acontece nos municípios independentemente se estes são governados por partidos que compóem a base aliada do governo ou não, gerando, portanto, dividendos políticos para o governo federal independentemente da vontade da gestão local.
35 Entrevistas com Vereadores 3 e 4, realizadas em 2012.

36 Entrevistas com Vereadores 5 e 6, realizadas em 2013.

37 Entrevista com Morador 2, realizada em 2013.

38 Entrevista com Morador 3, realizada em 2013.

39 Entrevista com Gestor Municipal 11, realizada em 2012. 
40 Entrevista realizada em 2012.

41 Entrevista com Construtora 1, em 2012. O "parceiro" mencionado seria um agente intermediário que atua na prospecção de terrenos para a construtora. Esse parceiro seria uma equipe ou indivíduo que intermedia a compra, geralmente em várias cidades, ganhando um percentual do valor do projeto.

42 Entrevistas com Agentes da Caixa 1 e 2, realizadas em 2012.

43 Entrevista com Vereador 7, realizada em 2012.

44 Entrevista com Gestor Municipal 11, realizada em 2012.
Como forma de obtenção de maior controle sobre a implementação do programa no território, a União sentiu a necessidade de se fazer mais presente nos municípios, o que pode ser percebido, principalmente, pela evolução do papel desempenhado pela Caixa Econômica Federal. Além de reiterar o papel de agente financiador, regulador e fiscalizador que o banco vem exercendo desde a extinção do BNH, o PMCMV o transformou em um importante ator no nível local, responsável por fazer o programa "rodar" e importante elo entre os agentes envolvidos - governo federal, empresas, governos locais e beneficiários. Os estudos de caso trouxeram vários exemplos dessa atuação no nível local.

De acordo com entrevistado da Construtora $5^{40}$, a Caixa teria sido o agente responsável por fazer com que atuassem no município de Jacareí, tendo buscado ela mesma uma construtora que estivesse interessada em produzir empreendimentos da Faixa 1 no município, que se encontrava com dificuldades em atrair interessados:

O processo para a nossa construtora chegar em Jacareí foi através do contato com o parceiro e com a Caixa regional [Gerência de Desenvolvimento urbano (GIDUR) de São José dos Campos]. O prefeito de Jacareí mostrou interesse, a CAIXA falou com o 'parceiro', que falou conosco. Tem casos que a GIDUR liga diretamente para o diretor da nossa construtora. O terreno, inclusive, já tinha sido prospectado pela CAIXA. ${ }^{41}$

Em outros casos, a Caixa atua como mediadora nas negociaçóes entre proprietários privados de terrenos e construtoras interessadas em realizar um determinado empreendimento, conforme entrevista com Agentes 1 e 2 da própria Caixa ${ }^{42}$.

No caso de Hortolândia ${ }^{43}$, há uma negociação para que famílias que não se enquadram na primeira faixa de renda do programa - mas que também não conseguem arcar com os produtos de mercado popular (Faixa 2) por terem uma renda ainda muito baixa - possam ser atendidas pelo Faixa 1. Note-se que essa decisão está sendo tomada entre a Secretaria de Habitação do município e a própria Gerência da Caixa na região.

Longe, portanto, de apenas regular o que pode ou náo ser feito nos empreendimentos financiados através do PMCMV, o banco tem, efetivamente, articulado os diversos atores para a sua implementação, até mesmo em função da necessidade de cumprir suas metas. A instituição e seus gerentes têm usado diferentes artifícios para alcançar esses objetivos, mesmo que, por vezes, as estratégias mobilizadas não dialoguem com as necessidades habitacionais existentes. Por exemplo, no município de Registro ${ }^{44}$, a Gerência da Caixa responsável pela contratação na região conseguiu modificar a meta inicial municipal de 142 para 1500 unidades. Essa possibilidade se apresentou já que a normativa do programa determina metas não para os municípios, mas para as gerencias regionais da Caixa. Isso permitiu transformar a meta não alcançada em Santos em unidades construídas em Registro, o que certamente não solucionou o déficit habitacional de Santos.

A Caixa tem assumido o importante papel de ser a presença federal nos municípios. A ampliação do crédito habitacional e a meta da construção de 3,4 milhóes de unidades habitacionais refletiram na ampliação da capilaridade da instituição pelo território brasileiro, constituindo presença marcante da União no plano local. Além de uma presença simbólica (já que suas agências são encontradas em praticamente todo território nacional e é a elas que a população se 
dirige para a finalizaçáo de seus contratos do PMCMV), a Caixa tem desempenhando, inclusive, funções de apoio técnico - como prospectar terrenos, elaborar projetos, sugerir melhorias técnicas, etc. ${ }^{45}$-, tal como caberia a um órgão executivo da administração pública direta.

Segundo entrevista ${ }^{46}$, o banco ampliou o número de funcionários e, consequentemente, sua capacidade de operação exatamente para poder proporcionar esse tipo de atuação, transformando a Vice-presidência de Governo (dentro da qual estão inseridas as GIDURs) a maior vice-presidência do Banco. O sentido desse considerável investimento por parte do Governo Federal está claro: fortalecer a estrutura institucional que garante o alcance das metas estipuladas para o programa, uma de suas principais fontes de capital político.

\section{AS EMPRESAS}

As relaçôes entre empresas e poder público encontradas durante a pesquisa no plano local reafirmaram a existência de uma simbiose. De um lado, as empresas do setor dependem fortemente do Estado para garantir seus ganhos permanentes; de outro, o Estado utiliza de forma keynesiana o investimento em habitação para alavancar suas políticas macroeconômicas e, ao mesmo tempo, garantir suas relaçóes de poder a partir do capital político gerado com essas operaçóes.

Esse é o caso do PMCMV, medida anticíclica que fez com que o Brasil sentisse apenas como uma "marolinha" ${ }^{7}$ as consequências da crise mundial, aquecendo a economia brasileira através da injeção de recursos no setor da construção civil. Enquanto o governo é beneficiado pela melhora na economia com a criaçáo de numerosos postos de trabalho e pela produção de milhares de unidades habitacionais - que funcionam como importantes geradores de capital político -, o setor da construção se beneficia com os novos arranjos produtivos para promoção habitacional disseminados por esse programa.

A partir dos estudos de caso, ficou evidente que esses novos arranjos têm permitido um maior protagonismo do setor empresarial na promoção habitacional. $\mathrm{O}$ empresariado é brindado com uma maior liberdade de escolha sobre onde, como e quando pretende atuar, proporcionando toda uma nova mobilidade para a realizaçáo de negócios por parte das empresas, além de viabilizar a ampliação de seus mercados.

Um primeiro exemplo dessa mobilidade mencionada em entrevistas ${ }^{48}$ é a migraçáo de empresas entre a produção propiciada pela $\mathrm{CDHU}$ e aquela proporcionada pelo PMCMV no estado de São Paulo. De acordo com as construtoras, o procedimento adotado pela CDHU era muito mais complexo e burocrático. O PMCMV teria eliminado e/ou facilitado vários desses procedimentos, pois seria muito melhor a compra do terreno (no caso do PMCMV) do que a espera pela doaçáo por parte da prefeitura (requisito no caso da CDHU). De acordo com empresários entrevistados ${ }^{49}$, com o PMCMV estaria mais fácil circular para produzir entre diferentes cidades. Caso esteja muito difícil em uma delas - em função de legislaçōes e/ou dificuldades em aprovações dos projetos -, as empresas simplesmente migram para outra.

É mencionado ${ }^{50}$, ainda, que a mobilidade trazida pelo programa possibilitaria que não estejam mais estritamente dependentes do preço da terra. Embora esse preço $^{51}$ continue a ser um ponto crucial do cálculo de viabilidade do empreendimento ${ }^{52}$, essa questâo pode ser resolvida pelo empresário ao desistir de produzir em
45 Entrevistas com Agente da Caixa 3 e Construtor 2, realizadas em 2012

46 Agente da Caixa 1, entrevistado em 2012

\begin{abstract}
47 Durante o auge da crise mundial iniciada nos Estados Unidos da América (EUA) em 2008, o então presidente Lula, para dar segurança aos investidores e garantir que suas medidas anticíclicas estavam corretas, declarou que a quebra de Wall Street em 2008 poderia ter sido um tsunami para os EUA, mas no Brasil ela estava mais para uma "marolinha". (ANDERSON, 2011).
\end{abstract}

48 Entrevistas com Construtoras 1,4 e 5 e Gestora Estadual 1, realizadas entre 2012 e 2013

49 Construtoras 1,4 e 5, realizadas entre 2012 e 2013

50 Entrevista com o Construtor 4, realizada em 2012

51 Segundo o Construtor 5 (entrevistado em 2012), "o valor do terreno nunca pode supe$\operatorname{rar} 6 \%$ do valor total do empreendimento".

52 Entrevistas com Construtoras 1,3 , 4 e 5, realizadas entre 2012 e 2013. 
53 Foram analisados os dados do TSE de doações para campanhas nacionais (presidência e estado de São Paulo) dos dois primeiros colocados na disputa e de seus comitês financeiros e diretórios partidários em 2002, 2006 e 2010. Também foram analisadas doações para campanhas municipais (nos seis municípios estudados) dos três primeiros colocados na disputa e de seus comitês e diretórios (incluindo diretórios estaduais e nacionais para eleições municipais) em 2008 e 2012.

54 Foram realizados levantamentos de dados apenas dos Diretórios Nacionais do PT e do PSDB em pleitos municipais, pelo fato desses partidos serem os mais recorrentes nos estudos de caso. Além disso, são importantes para demonstrar que, embora de espectros políticos diferentes, ambos recebem vultosas doações de campanha de empresas do campo urbano.

55 O TSE disponibiliza os dados dos diretórios nacionais e estaduais em eleições municipais apenas para o ano de 2012. um determinado município e migrar para outro em que o preço seja menor. Isso significa que, em função de uma maior rentabilidade da iniciativa privada, estarse-á deixando de combater o déficit habitacional de um determinado município.

Mesmo diante do aumento do protagonismo por parte do empresariado proporcionado pelo PMCMV, ainda é necessário que estabeleçam um mínimo de relação com as prefeituras, detentoras do poder de aprovação de projetos. Nesse sentido, uma hipótese de pesquisa era de que uma importante faceta dessa relação se daria através das doaçôes eleitorais por empresas. Em um país em que as campanhas eleitorais mostram-se extraordinariamente caras (SAMUELS, 2006), a arrecadação de doaçôes é cada vez mais central.

Levantamos e processamos os dados disponibilizados pelo Tribunal Superior Eleitoral (TSE) ${ }^{53}$, além de abordarmos o tema em entrevistas. Através dessa exploração, constatou-se que não são relevantes as doações feitas diretamente por construtoras na maioria dos municípios estudados, tendo em vista que, em média, no máximo $14 \%$ dos recursos dos candidatos provieram de empresas ligadas à área. Entretanto, é grande a representatividade dessas doaçóes para os diretórios nacionais e estaduais do $\mathrm{PT}$ e do $\mathrm{PSDB}^{54}$ nos pleitos municipais, que chega a ser $54 \%$ do total arrecadado.

Embora não se disponha de uma série histórica para fazer afirmações categóricas sobre o assunto ${ }^{55}$, é importante pensar o significado disso em termos políticos. É expressivo o volume de recursos que os diretórios nacionais e estaduais dispóem para distribuir entre seus diversos candidatos locais, disponibilizando-os de acordo com a importância do município para o partido, com a viabilidade eleitoral de seu candidato, etc. Assim, as doaçôes de campanha realizadas por empresas não são apenas recursos utilizados para manutenção do entrelaçamento entre setor empresarial e o Estado mas também para manutenção do controle das altas esferas dos partidos sobre suas bases.

Claro, há casos em que as lideranças municipais também possuem força política suficiente para captar recursos que financiem suas campanhas independentemente dos altos escalóes partidários. Nos municípios estudados, a maioria dos candidatos recebia, em volume e representatividade, doações pouco relevantes de empresas da área, à exceção dos municípios de Osasco e de Praia Grande, que possuem maior população e dinâmica econômica. Apesar de ainda dependerem dos diretórios estadual e nacional dos seus partidos, neles as doaçôes diretamente feitas aos candidatos por empresas apresentaram relevância, principalmente no caso de Praia Grande, em que $51 \%$ dos mais de $\mathrm{R} \$ 2$ milhóes arrecadados pelo candidato vencedor provêm do setor empresarial da construção.

Uma hipótese, nesse sentido, que explicaria a valorização da doação aos diretórios estaduais e nacionais é de que as empresas têm investido mais naqueles atores que realmente possuem o poder de influenciar as decisóes relativas a essas políticas (IACOVINI, 2013; LAZZARINI, 2011), ou seja, elas têm investido mais no plano partidário federal do que no local (mesmo em eleições municipais), uma vez que é justamente no plano federal que são tomadas as grandes decisôes acerca das políticas habitacionais. Assim, mesmo não havendo uma significativa ligação direta entre empresas e poder público no plano local através de doaçôes de campanha, essas doaçôes continuam a ser parte importante do jogo político que conforma a política habitacional executada nos municípios. 


\section{OS MOVIMENTOS SOCIAIS DE MORADIA}

Se, em 1988, a Constituição Federal já consagrava dispositivos que institucionalizavam a participação direta dos cidadãos como forma e, em alguns casos, requisito da realização do princípio democrático, isso ganha efetivamente força no campo urbano e habitacional a partir da aprovação do Estatuto da Cidade, que incluiu na agenda política a democratização do planejamento através da adoção de um modelo tripartite de elaboração e fiscalização da política urbana, com a sociedade civil, empresários e governo pactuando seus rumos.

A instituiçáo do Ministério das Cidades, do Conselho Nacional das Cidades e das Conferências Nacionais das Cidades expressou o esforço, por parte do governo federal, da constituição de um lócus para a formulação e implementação participativas de uma política urbana (SANTOS JR.; NASCIMENTO; FERREIRA, 2008; MARICATO, 2012). Para os movimentos sociais envolvidos na eleição de Lula, representava a possibilidade de avançar na democratização da gestão urbana e habitacional e de, finalmente, fazerem parte do processo de formulação e implementaçáo de tais políticas.

Outra importante iniciativa foi a criação do SNHIS, que determinava a instituição de conselho participativo para a gestão dos recursos em todas as esferas federativas. Houve, entâo, uma proliferação de Conselhos Municipais de Habitação, através dos quais se esperava que fossem estabelecidas arenas de discussão e deliberação das políticas habitacionais no âmbito local. Essa estratégia foi em alguma medida bem sucedida, tendo em vista, por exemplo, que em todos os municípios estudos de caso existem ou existiram Conselhos Municipais de Habitação. Mesmo naqueles em que sequer há uma secretaria de habitação, caso de Jacareí e Registro, o Conselho foi, ao menos formalmente, criado a partir de 2005.

Contudo, isso não significou a inclusão de movimentos e entidades da sociedade civil organizada na formulação e implementação da política habitacional. Em alguns municípios estudados, o Conselho não se reúne há no mínimo cinco anos, casos de Ferraz de Vasconcelos e Registro, tendo praticamente sido criado apenas como cumprimento ao requisito do SNHIS.

Mesmo nos demais municípios, pouco se constatou de avanço no sentido da incidência desses Conselhos sobre os rumos das políticas municipais. Em Hortolândia, o Executivo municipal admite que a institucionalização do Conselho de Habitaçáo é mera formalidade, constituindo uma instância de representação que costuma simplesmente aprovar os projetos do governo sem grandes debates ${ }^{56}$, visão corroborada por um vereador do município para quem "poucos membros [do Conselho] costumam debater as pautas e encaminhamentos. A maioria simplesmente aprova o que a Prefeitura envia sem discutir ou questionar" ${ }^{57}$. Em Jacareí, a mesma crítica é feita por representante da sociedade civil, que afirma que o conselho "[acabou] virando 'chapa branca'. Existem algumas ONGs [Organizações Não Governamentais], mas que quase sempre ficam nas mãos de um ou outro vereador" ${ }^{\prime 5}$.

Mesmo em Osasco, no qual se encontrou um Conselho de Habitação mais ativo, a política segue uma lógica pautada pela oferta de recursos federais, realizando ações no território de acordo com o que é ofertado em cada momento pelos programas federais. Dessa forma, o Conselho possui pouca ingerência sobre o processo, sendo mais um espaço de apresentação de demandas e de referendar as açôes propostas
56 Entrevista com Gestor Municipal 5, realizada em 2012.

57 Entrevista com Vereador 7, realizada em 2012.

58 Entrevista com Representante da Sociedade Civil 1, realizada em 2012 
59 Entrevistas com Representantes da Sociedade Civil 2 e 3, realizadas em 2012.

60 Dados obtidos através da aplicação de questionários com mais de 100 famílias moradoras do empreendimento no âmbito da pesquisa "Ferramentas para avaliação da inserção urbana dos empreendimentos do PM$\mathrm{CMV}^{\prime \prime}$, realizada pela equipe do LabCidade. pela gestáo municipa ${ }^{59}$. Esse cenário náo é estranho se levado em consideração que não é reservado qualquer papel para os conselhos no PMCMV, ação priorizada pelos municípios.

Apesar disso, não se pode dizer que esses processos não implicaram em mudanças no panorama político. Se tais arenas foram sendo desconstituídas aos poucos, pelo menos durante um certo período elas foram espaços importantes para lançar esses movimentos como interlocutores, transformando-os em atores da política habitacional em nível nacional e, em alguns casos, local.

Indicadores importantes disso são encontrados no próprio PMCMV. Após o seu lançamento, o programa teve que incorporar, por pressão dos movimentos de moradia, uma modalidade específica (PMCMV Entidades), voltada ao financiamento de açôes de produção habitacional encabeçadas por organizaçôes sociais. Embora o aporte de recursos nessa modalidade seja relativamente pequeno diante do montante global do programa (2\% apenas) (RODRIGUES, 2013), não se pode negar que sua existência está diretamente relacionada ao fato de que tais movimentos possuem hoje um novo status no âmbito político e que sua adoção foi uma condição para que estes permanecessem na base de apoio do governo.

Outro ganho que expressa essa nova posição é a crescente participação desses movimentos na formação das listas de beneficiários da Faixa 1 do PMCMV em diferentes municípios, os quais têm reservado um percentual das unidades produzidas para atendimento de famílias indicadas por movimentos sociais. Em Osasco, por exemplo, mais de $15 \%$ dos beneficiários do empreendimento Flor de Jasmim foram indicados por movimentos ${ }^{60}$.

É importante destacar que os ganhos com o programa obtidos pelos movimentos são importantes para que estes possam atender às suas bases, compostas principalmente por famílias em busca de uma moradia. Eles demonstram ainda que, embora os movimentos continuem a não participar efetivamente dos processos decisórios da política habitacional, eles foram, ao menos, incluídos na lista de atores contemplados com a distribuição dos benefícios dos investimentos na área. Assumindo uma parcela pouco significativa das moradias produzidas e utilizando, sobretudo, sua representação nos conselhos, os movimentos passaram a integrar o jogo do controle da distribuição dos ativos políticos do programa, juntamente com lideranças e grupos partidários que compóem a base do governo.

\section{CONCLUSÃO}

Inicialmente buscávamos explorar os atores, arenas e processos envolvidos em investimentos habitacionais e compreender se esses investimentos convergiam ou não com os processos de planejamento e gestão participativos. Nossa hipótese consistia de que não havia essa convergência em função da disponibilidade reduzida de recursos próprios municipais, levando a uma dependência municipal das transferências provenientes dos governos federal e estadual, as quais seriam pautadas por programas centralizados em outras esferas e por processos decisórios de formulação e implementação que não passavam pelas instâncias participativas dos municípios.

A pesquisa demonstrou que realmente inexiste essa convergência, tendo em vista que os processos e arenas participativas encontradas apenas existem formalmente ou, 
quando existem de fato, pouco incidem sobre os processos decisórios no plano local. Dessa forma, essas instâncias não chegaram a ser efetivadas da forma como haviam sido idealizadas - espaços nos quais seriam formuladas, discutidas, pactuadas e fiscalizadas as políticas urbanas e habitacionais. Mesmo assim, elas possibilitaram aos movimentos sociais de moradia que se tornassem efetivamente atores envolvidos no processo. Sua participação, contudo, tem se dado muito mais abocanhando uma parcela na forma tradicional de distribuição dos benefícios e ativos desse programa do que no processo decisório sobre a formulação da política.

Por fim, concluímos que não é a falta de recursos financeiros e a dependência de outros entes federativos que têm impedido a formulação e implementação de açóes autônomas, aderentes às necessidades locais e pactuadas nos âmbitos de participação instituídos, pois os municípios possuem, no mínimo, uma pequena margem financeira que permitiria a sua realização. $\mathrm{Na}$ verdade, trata-se mais de uma postura pragmática dos governos municipais que, aderindo ao modelo PMCMV com um mínimo de esforço institucional, asseguram ganhos importantes (de ordem política, financeira, etc.) aos principais atores da política: a própria gestão municipal, os políticos envolvidos, as instâncias partidárias mais amplas das quais eles fazem parte, as empresas e, até mesmo, os movimentos de moradia. Nesse sentido, para que fazer de outra forma?

\section{BIBLIOGRAFIA}

ANDERSON, P. O Brasil de Lula. Novos Estudos - CEBRAP, n. 91, p. 23-52, nov. 2011.

ARRETCHE, M. Estado Federativo e Politicas Sociais: determinantes da descentralizaçáo. Rio de Janeiro: Renavan; São Paulo: FAPESP, 2000.

Quem taxa e quem gasta: a barganha federativa na federação brasileira. Revista de Sociologia e Politica, Curitiba, n. 24, p. 69-85, jun. 2005.

(Coord.). Capacidades Administrativas dos Municipios Brasileiros para a Politica Habitacional. Brasília: Ministério das Cidades; São Paulo: CEM/CEBRAP, 2012.

AZEVEDO, S. Desafios da Habitação Popular no Brasil: políticas recentes e tendências. In: CARDOSO, A. L. (Coord.). Habitação Social nas Metrópoles Brasileiras: Uma avaliação das políticas habitacionais em Belém, Belo Horizonte, Porto Alegre, Recife, Rio de Janeiro e São Paulo no final do século XX. Porto Alegre: ANTAC, 2007. p. 13-41. (Coleção Habitare).

BONDUKI, N. Origens da habitação social no Brasil. São Paulo: Estação Liberdade, 1998.

BRASIL. Ministério das Cidades. Secretaria Nacional e Habitação. Avanços e Desafios: Política Nacional de Habitação. Brasília: Ministério das Cidades, Secretaria Nacional de Habitação, 2010.

CALDEIRA, J. As determinantes politicas dos processos de urbanização de assentamentos precários. 2014. No prelo.

CAMARGOS, R. Estado e empreiteiros no Brasil: uma análise setorial. 1993. 173 f. Dissertação (Mestrado em Ciência Política) - Instituto de Filosofia e Ciências Humanas, Universidade Estadual de Campinas, Campinas, 1993.

CARDOSO, A. L.; ARAGÃO, T. A.; ARAUJO, F. S. Habitação de Interesse Social: política ou mercado? Reflexos sobre a construção do espaço metropolitano. In: ENCONTRO NACIONAL DA ANPUR, 14., 2011, Rio de Janeiro. Anais do XIV Encontro Nacional da ANPUR. Rio de Janeiro: ANPUR, 2011.

DENALDI, R. Política Habitacional e Urbana: avanços e impasses. In: ENCONTRO NACIONAL DA ANPUR, 15., 2013, Recife. Anais do XV Encontro Nacional da
Raquel Rolnik é arquiteto e urbanista e mestre em Arquitetura e Urbanismo pela Universidade de São Paulo (USP); doutora na Graduate School of Arts and Science History Department pela New York University; professora da Faculdade de Arquitetura e Urbanismo (FAU) da USP; coordenadora do Laboratório Espaço Público e Direito à Cidade (LabCidade); bolsista de produtividade do Conselho Nacional de Desenvolvimento Científico e Tecnológico (CNPq), Brasil. E-mail:_raquelrolnik@ gmail.com.

Rodrigo Faria Gonçalves lacovini é bacharel em Direito pela Universidade Federal do Ceará (UFC); mestre em Arquitetura e Urbanismo pela Universidade de São Paulo (USP); pesquisador do Laboratório Espaço Público e Direito à Cidade (LabCidade) da Faculdade de Arquitetura e Urbanismo (FAU) da USP, Brasil.

E-mail: rfgiaco@yahoo. com.br.

Danielle Klintowitz é arquiteta e urbanista pela Universidade Presbiteriana Mackenzie (UPM); mestre em Urbanismo pela Pontifícia Universidade Católica de Campinas (PUCCampinas); doutoranda em Administração Pública e Governo pela Fundação Getúlio Vargas (FGV); coordenadora de Urbanismo do Instituto Pólis, Brasil. E-mail: daniklin@gmail. com.

Artigo recebido em maio de 2014 e aprovado para publicação em julho de 2014 
CONSTRUIR POLÍTICAS O U "RODAR” PROGRAMAS?

ANPUR. Recife: ANPUR, 2013.

IACOVINI. R. F. G. Rodoanel Mario Covas: atores, arenas e processos. 2013. 211 f. Dissertação (Mestrado em Arquitetura e Urbanismo) - Faculdade de Arquitetura e Urbanismo, Universidade de São Paulo, São Paulo, 2013.

IPEA - INSTITUTO DE PESQUISA ECONÔMICA APLICADA. O planejamento da habitação de interesse social no Brasil: desafios e perspectivas. Brasília: IPEA, 2011. (Comunicados do IPEA, 118).

LAZZARINI, S. Capitalismo de Laços. Rio de Janeiro: Elsevier, 2011.

LOUREIRO, M. R.; MACÁRIO, V.; GUERRA, P. Democracia, arenas decisórias e politicas públicas: o Programa Minha Casa Minha Vida. Brasília: IPEA, out. 2013 (Textos para Discussão, 1886).

MARICATO, E. O impasse da politica urbana no Brasil. Petrópolis: Vozes, 2012.

MELO, M. A.; JUCÁ FILHO, A. Políticas públicas para as áreas urbanas: o impacto da crise fiscal e das transformaçōes institucionais. In: ENCONTRO NACIONAL DE ESTUDOS POPULACIONAIS. 7., 1990, Caxambu. Anais do VII Encontro Nacional de Estudos Populacionais. Caxambu: ABEP, 1990.

NUNES, E. O. A gramática política do Brasil: Clientelismo, corporativismo e insulamento burocrático. 4. ed. Rio de Janeiro: Garamond, 2010.

RODRIGUES, E. A Estratégia Fundiária dos movimentos populares na produção autogestionária da moradia. 2013. 233 f. Dissertação (Mestrado em Arquitetura e Urbanismo) - Faculdade de Arquitetura e Urbanismo, Universidade de São Paulo, São Paulo, 2013.

ROLNIK, R.; KLINTOWITZ, D.; IACOVINI, R. F. G. Financiamento e processos decisórios: em busca das determinantes da política de desenvolvimento urbano no Brasil. In: ENCONTRO ANUAL DA ANPOCS, 35., 2011, Caxambu. Anais do $35^{\circ}$ Encontro Anual da ANPOCS, 2011. Caxambu: ANPOCS, 2011.

RONALD, R. The ideology of home ownership. Basingstoke: Palgrave Macmillan, 2008.

ROYER, L. Politica Habitacional no Estado de São Paulo: estudo sobre a Companhia de Desenvolvimento Habitacional e Urbano do Estado de Sáo Paulo, CDHU. 2002. 209 f. Dissertação (Mestrado em Arquitetura e Urbanismo) - Faculdade de Arquitetura e Urbanismo, Universidade de São Paulo, São Paulo, 2002.

SAMUELS, D. Financiamentos de campanhas no Brasil e propostas de reforma. In: SOARES, G.; RENNÓ, L. (Org.). Reforma politica: liçōes da história recente. Rio de Janeiro: Ed. FGV, 2006. p. 133-153.

SANTOS JR., O. Cidade, cidadania e planejamento urbano. Desafios na perspectiva da reforma urbana. In: FELDMAN, S.; FERNANDES, A. (Org.). O Urbano e o regional no Brasil Contemporâneo: Mutaçôes, tensōes, desafios. Salvador: EDUFBA, 2007. p. 293-314.

.; NASCIMENTO, C.; FERREIRA, R. O sistema nacional de desenvolvimento urbano: avanços e limites para a descentralizaçáo dos canais de participaçáo. In: FILGUEIRAS, C.; FARIA, C. A. (Org.). Governo local, politica pública e participação na América do Sul. Belo Horizonte: PUC-Minas, 2008. p. 273-294.

A B S T R A C T: This article analyses the actors, arenas and processes actually involved in housing investments in São Paulo's municipalities. The main question is about the convergence between these investments and the participatory processes developed in the last decade. The absence of convergence between these two elements formed our initial hypothesis. Although it has been confirmed, we have found that the reason for this mismatch was not linked to the limited availability of the municipalities' financial resources or to their low institutional capabilities as we have initially imagined. The lack 
of initiative to implement autonomous actions binded to local necessities and agreed upon in established participatory fields as well as the full adherence of the municipalities to the Minha Casa, Minha Vida program result from an institutional pragmatic attitude, since a minimal institutional effort is required from the municipal governments in order to ensure significant gains to the main players in this policy.

K E Y W O R D S : housing policy; municipal autonomy; decision-making processes; participative arenas; Programa Minha Casa, Minha Vida. 